\title{
PENGARUH SOSIAL MEDIA YOUTUBE TERHADAP PEMEROLEHAN BAHASA ANAK USIA 3-4 TAHUN (STUDI PADA ANAK SPEECH DELAY)
}

\author{
Mulia Kurniati $^{1}$, Nuryani ${ }^{2}$ \\ Pendidikan Bahasa dan Sastra Indonesia \\ Fakultas Ilmu Tarbiyah dan Keguruan \\ UIN Syarif Hidayatullah Jakarta \\ Mulia.kurniati4117@mhs.uinjkt.ac.id
}

\begin{abstract}
ABSTRAK: Tujuan dalam penelitian ini adalah untuk mendeskripsikan pengaruh sosial media youtube terhadap pemerolehan bahasa anak usia 3-4 tahun yang dilakukan pada anak speech delay (keterlambatan bicara). Hal tersebut didasari atas pemahaman bahwa kemajuan teknologi yang dilengkapi fitur-fitur canggih seperti YouTube akan makin mempermudah kehidupan bersosial manusia. Demikian juga pada anak-anak yang masih dalam tahap pemerolehan bahasa. YouTube menjadi salah satu media yang menarik serta memiliki pengaruh dalam proses pemerolehan bahasa anak, terlebih bagi anak yang mengalami keterlambatan bicara. Penelitian ini menggunakan pendekatan kualitatif deskriptif yaitu memaparkan sebuah situasi yang disajikan dalam bentuk uraian naratif. Responden penelitian ini adalah $\mathrm{H}$ yang sedang berada dalam fase fonologis dan fase sintaksis. Berdasarkan hasil penelitian dapat disimpulkan bahwa media sosial Youtube memiliki pengaruh yang signifikan pada pemerolehan bahasa anak khususnya bagi anak speech delay. Banyaknya perbendaharaan kata yang ada di dalam media Youtube bisa mempengaruhi pemerolehan bahasa responden. Akan tetapi, sejauh ini, karena ada faktor eksternal maka responden mengalami kesulitan dalam menerima sejumlah stimulus positif dari media Youtube.
\end{abstract}

KATA KUNCI: YouTube; Speech delay; pemerolehan bahasa.

\section{YOUTUBE SOCIAL MEDIA EFFECTS ON CHILDREN'S ACQUISITION LANGUAGE 3-4 YEARS OLD (STUDY IN CHILDREN SPEECH DELAY)}

\begin{abstract}
The purpose of this study is to describe the influence of YouTube on language acquisition in 3-4 years old toddler which having speech delay (late in speaking). This is based on the technology with features that are equipped with YouTube will further facilitate the social life of humans especially for children who are still in the language acquisition stage. YouTube has become an interesting medium and has a role in the process of acquiring children's language, especially for children who have speech delay. This study uses a qualitative descriptive study that presents a discussion presented in the form of narrative descriptions. Respondents of this study are $\mathrm{H}$ who are in phonological and syntactic phases. Based on the results of the study it can be concluded that social media Youtube has a significant effect on language acquisition specifically for children who are having a speech delay. The amount of vocabulary in Youtube can influence the acquisition of the respondent's language. However, beyond this, due to external factors, respondents have difficulty for receiving positive stimulus from YouTube.
\end{abstract}

KEYWORDS: YouTube; Speech delay; language acquisition.

\begin{tabular}{lccc}
\hline Diterima: & Direvisi: & Disetujui: & Dipublikasi: \\
15-01-2020 & $17-03-2020$ & $11-03-2020$ & $31-03-2020$ \\
Pustaka & Kurniati, M., \& Nuryani, N. (2020). PENGARUH SOSIAL MEDIA YOUTUBE TERHADAP \\
\multicolumn{4}{c}{ PEMEROLEHAN BAHASA ANAK USIA 3-4 TAHUN (STUDI PADA ANAK SPEECH } \\
& DELAY). Fon: Jurnal Pendidikan Bahasa dan Sastra Indonesia, 16(1), 29-38. \\
DOI & : https://doi.org/10.25134/fjpbsi.v16i1.2494 & \\
\hline
\end{tabular}

\section{PENDAHULUAN}

Perkembangan zaman membuat pengaruh besar terhadap kehidupan manusia. Perkembangan arus globalisasi telah menciptakan teknologi-teknologi canggih yang dahulunya tidak pernah terpikirkan dalam benak manusia. Zaman dahulu, tidak pernah terpikirkan oleh 
manusia bahwa bisa berkomunikasi dengan mudah apabila kedua subjek berada di dalam jarak yang cukup jauh. Setelah penemuan telepon Oleh Alexander Grahambell, maka komunikasi dengan orang yang berjarak jauh tidak pernah dirisaukan lagi, karena dengan memiliki alat bernama telepon, manusia sudah bisa mengutarakan maksud.

Apabila disebutkan, masih banyak lagi pengaruh globalisasi terhadap hidup manusia, dan mungkin apabila teknologi-teknologi itu ditiadakan sekarang, kehidupan manusia pasti akan berubah seratus persen, karena saat ini manusia hidup dalam ketergantungan pada teknologi-teknologi canggih. Sedikit sekali mereka yang dengan sukarela menggunakan benda-benda konvensional dengan alasan hanya mempersulit keadaan yang sudah jelas sudah dipermudah.

$$
\text { Sebelumnya, }
$$

sudah

dipaparkan bahwa arus globalisasi seperti telepon sudah membawa pengaruh besar terhadap hidup manusia, bahkan saat ini telepon sudah banyak bertransformasi mulai dari segi bentuk dan cara penggunaan. Saat ini telepon sudah tidak lagi digunakan dengan satu fungsi melainkan multifungsi.

Fitur-fitur terbaru di dalam telepon diperbanyak, maka makin mudah saja hidup manusia. Meskipun kecanggihan telepon utamanya adalah bisa mendekatkan sesuatu yang dasarnya jauh. Maka, dari sini dimulailah muncul pengaruh-pengaruh dari canggihnya telepon tersebut, yaitu mempersempit kehidupan sosial manusia. Meskipun kehidupan sosial manusia bisa digantikan dengan ecanggihan telepon tapi hasilnya tentu berbeda, tidak akan sama.

Dalam fitur telepon, bisa ditemui aplikasi-aplikasi penunjang kehidupan sosial manusia, salah satunya Youtube. Pengertian Youtube telah kita pahami bersama sebagai salah satu alat komunikasi yang di dalamnya berisi sejumlah gambar atau video dengan suara. Banyaknya jumlah video di Youtube tergantung dengan banyaknya para pengirim video ke Youtube, siapa saja bisa mengaksesnya, bahkan sekarang, anak-anak dengan mudahnya mengakses tanpa perlu bimbingan orang dewasa.

Pengaruh sosial media ini berimbas tidak hanya bagi mereka yang sudah dewasa, melainkan anak-anak. Apabila berlebihan, pengaruh negatif bukan tidak mungkin merambas pada diri anak-anak. Tapi, positifnya, kerapkali ditemukan anak-anak yang cenderung pintar karena sering menonton dan meniru apa yang ada di Youtube, maka penulisan ini akan melihat pengaruh-pengaruh yang timbul dengan penggunaan sosial media Youtube terhadap anak-anak.

Tulisan ini merupakan sebuah kajian Psikolinguistik. Psikolinguistik adalah telaah mengenai produksi (sintesis) dan rekognisi (analisis) (Lyons dalam Nuryani, 2013, hlm. 6). Psikolinguistik adalah suatu ilmu yang meneliti bagaimana sebenarnya para pembicara atau pemakai bahasa membentuk atau membangun atau mengerti kalimatkalimat bahasa tersebut. (Bach dalam Nuryani, 2013, hlm.6).

Salah satu bidang penelitian psikoliguistik adalah pemerolehan bahasa pada anak. Pemerolehan bahasa (language acquisition) adalah proses penguasaan bahasa yang dilakukan oleh anak secara natural pada waktu dia belajar bahasa ibunya (native language). (Dardjowidjojo, 2003, hlm. 225). Pemerolehan bahasa selalu di dapat seorang anak apapun keadaan anak tersebut, salah satunya adalah anak-anak yang memiliki gangguan berbahasa.

Gangguan keterlambatan bicara adalah istilah yang dipergunakan untuk mendeskripsikan adanya hambatan pada kemampuan bicara dan perkembangan bahasa pada anak-anak, tanpa disertai 
keterlambatan aspek perkembangan lainnya. (Subyantoro, 2013, hlm. 250)

Ada enam penyebab keterlambatan bicara, di antaranya adalah

1) retardasi mental, retardasi mental biasanya diakibatkan oleh keterlambatan proses pematangan saraf dalam kandungan, gangguan berbicara ekspretif, autisme, gangguan perkembangan yang mengenai banyak sistem, keterlambatan perkembangan global.

2) gangguan pendengaran, anak yang menderita tuli akibat infeksi di daerah telinga dapat pula menderita keterlambatan bicara. Hal ini berhubungan dengan bagaimana otak memahami, meniru, dan menggunakan bahasa yang pernah didengarnya dan,

3) keterlambatan maturbasi atau keterlambatan bicara fungsional. Keterlambatan akibat gangguan pada otot bicara dapat diidentifikasi dari cara anak melafalkan bicara yang tak jelas dan tak berujung sempurna, otaknya sudah memerintahkan dan memberikan stimulus untuk menjawab dengan benar, tapi kata yang keluar dari mulut tidak jelas karena adanya gangguan neurologis atau persarafan.

4) Keterbatasan kognitif, biasanya, anak yang mengalami gangguan ini kurang mampu melakukan aktivitas sederhana, seperti mengikat tali sepatu.

5) Mengalami gangguan Pervasif, biasanya gangguan ini terjadi pada anak yang mengalami ADD (Attention Devisit Disorder), ditandai dengan aktivitas lain seperti sulit berkonsentrasi, gangguan ini perlu di bawa ke ahli.

6) Kurangnya interaksidan komunikasi dengan orang tua dan lingkungan sekitar, keadaan-keadaan seperti lingkungan perumahan, kemiskinan, kurang gizi, kurang rangsangan orang tua dapat menimbulkan gangguan berbicara, ini membuat anak kekurangan perbendaharaan dalam katakata, anak-anak kurang dipacu logis, dan lain-lain (Subyantoro, 2013, hlm. 263264).

Berdasarkan penelitian yang telah dilakukan oleh Lestari didapatkan simpulan bahwa pada anak usia 3 tahun seharusnya telah memiliki kesadaran fonologis terutama pada keterampilan pemenggalan suku kata. Pada keterampilan tersebut anak usia 3 tahun masih dipengaruhi oleh kemampuan pelafalan fonem seperti fonem $/ \mathrm{r} /$. Meskipun demikian, tidak dapat dikatakan juga bahwa anak usia 3 tahun yang belum memiliki kesadaran fonologis dikategorikan sebagai anak yang mengalami keterlambatan bicara. Lebih dari itu, perlu adanya pendeteksian dini agar mengetahui apakah keterlambatan bicara pada anak tersebut sesuatu yang fungsional atau nonfungsional. (Subyantoro, 2013, hlm. 254)

Keterlambatan

fungsional merupakan yang paling umum terjadi, biasanya disebut keterlambatan motorik yaitu dari pusat syaraf, dan biasanya terdapat riwayat keluarga. Biasanya keterlambatan fungsional akan membaik setelah usia dua tahun, dan keterlambatan nonfungsional bisa dilakukan dengan bantuan medis. (Subyantoro, 2013, hlm. 256-257).

Secara tradisional, pemerolehan bahasa dibagi menjadi empat yaitu 1) tahap pralinguistik (0-12 bulan) bayi sudah bisa menggeram dan menghasilkan banyak suara 2) tahap satu-kata (12-18 bulan) ditandai dengan anak yang sudah belajar menggunakan satu kata yang mewakili idenya, pada tahap ini orang tua atau orang lain juga perlu memperhatikan aktivitas anak dan unsur-unsur nonlinguistik lainnya seperti gerak, isyarat, ekspresi, dan benda yang ditunjuk si anak. 3) tahap dua-kata (18-24 bulan) ditandai dengan anak yang sudah mengombinasikan dua kata dalam bentuk ucapan pendek tanpa kata depan, kata tunjuk dan bentuk lainnya, 4) tahap 
banyak kata (3-5 tahun) ditandai dengan kemampuan seorang anak membuat kalimat pertanyaan negatif, kalimat majemuk dan berbagai bentuk kalimat. dalam anak berusia empat tahun, tidak muncul dalam diri $\mathrm{H}$, yaitu seperti tuturan yang mulai panjang dan tata bahasanya lebih teratur. Dia tidak hanya menggunakan dua kata, tetapi tiga atau lebih. Pada usia 3-4 tahun tuturan anak mulai panjang dan tata bahasanya teratur. (Ingram dalam Nuryani, 2013, hlm. 9194).

Pemerolehan bahasa anak dibagi menjadi beberapa tataran kebahasaan, yaitu 1) Fase Fonologis (0-2 tahun), pada tahap ini anak bermain dengan bunyibunyi bahasa dan mulai mengoceh sampai menyebutkan kata-kata sederhana 2) Fase Sintaksis (2-7 tahun), pada tahap ini anak menunjukkan kesadaran gramatis dan berbicara menggunakan kalimat 3) Fase Semantik (7-11 tahun), pada tahap ini anak dapat membedakan kata sebagai simbol dan konsep yang terkandung dalam kata. (Zuchdi dan Budiash dalam Nuryani, 2013, hlm. 107)

Tahapan perkembangan berbicara pada anak yang normal dikenali dengan 1) usia 12-15 bulan; kalimat belum jelas, dia mulai mengucapkan beberapa patah kata tapi tidak jelas 2) usia 16-17 bulan; anak sudah dapat menguasai 7-20 kata termasuk kata yang baru di dapatnya 3) usia 18 bulan; anak sudah dapat merangkai dua kata menjadi kalimat sederhana 4) usia 21030 bulan; anak sudah mencapai lebih dari 50 kata 5) usia 36 bulan, anak sudah bisa menguasai 250 kata dan membentuk kalimat yang terdiri dari tiga kata.(Subyantoro, 2013, hlm. 262).

Bukan sesuatu yang mustahil apabila seorang anak mendapatkan pengetahuan baru mengenai perbendaharan kata lewat sosial media Youtube, seperti orang dewasa, anakanakpun pandai menyerap informasi dan pengetahuan dari apa yang ia lihat dan dengar -dalam hal ini sosial media Youtube - maka sesuatu yang baru apabila sosial media Youtube dapat mempengaruhi pemerolehan bahasa anak-anak yang memiliki riwayat keterlambatan berbicara (speech delay).

Penelitian mengenai pemerolehan bahasa pada anak-anak sudah banyak dilakukan, seperti yang dilakukan oleh Tati Hernawati dengan penelitiannya yang berjudul "Pengembangan Kemampuan Berbahasa dan Berbicara Anak Tunarungu", Tati menemukan bahwa kemampuan berbahasa seorang anak tunarungu dapat dikembangkan berdasarkan pemerolehan bahasanya dengan cara mendengar dan bentuk visualisasi. (Hernawati, 2007)

Lalu penelitian mengenai pemerolehan bahasa juga dilakukan oleh Prima Gusti Yanti dengan judul "Pemerolehan Bahasa Anak: Kajian Aspek Fonologi Pada Anak Usia 2 - 2,5 Tahun", penelitian menunjukkan bahwa narasumber (TPM) telah menguasai

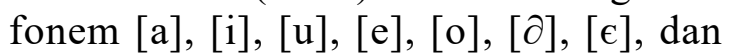
$[\mathrm{O}]$, Bunyi vokal rangkap, huruf konsonan, TPM melakukan pola substitusi untuk mengucapkan fonemfonem yang belum dikuasainya, seperti fonem [f], [v], $[\mathrm{z}]$, dan [x]. Munculnya berbagai variasi dalam pemerolehan fonologi TPM sebagian besar disebabkan oleh belum sempurnanya alat ucap TPM. (Yanti, 2016).

Sejauh ini, penelitian mengenai pemerolehan bahasa dengan media sebuah kecanggihan teknologi yaitu Youtube dan subjek penelitiannya adalah anak yang mengalami keterlambatan berbicara belum dilakukan, maka dengan adanya tulisan ini, diharapkan dapat menambah referensi dalam dunia kajian psikolinguistik dan akan muncul kembali penelitian-penelitian yang lebih relevan. 


\section{METODE}

Penelitian ini merupakan Penelitian ini menggunakan metode deskriptif kualitatif. Penelitian menggunakan pendekatan kualitatif sifatnya deskriptif analitis. Data yang diperoleh seperti hasil pengamatan, wawancara, pemotretan, analisis dokumen, catatan lapangan, disusun peneliti di lokasi penelitian, tidak dituangkan dalam bentuk angka-angka. Hasil analisis berupa pemaparan mengenai situasi yang diteliti kemudian disajikan dalam bentuk uraian naratif. Jadi, pendekatan kualitatif ini digunakan untuk mendeskripsikan analisis tentang pengaruh media Youtube terhadap Pemerolehan Bahasa Anak pengidap Speech Delay usia 3-4 tahun. (Dewi, Suandi, dan Wisudariani, 2016, hlm. 5). Subjek penelitian dalam tulisan ini adalah seorang anak bernama $\mathrm{H}$ atau diinisialkan dengan huruf $\mathrm{H}$ yang berumur 4 tahun. $\mathrm{H}$ mengalami keterlambatan berbicara, di rumah ia suka sekali menonton televisi dan video di Youtube. Saat menonton, ia cenderung pasif dan fokus dan tidak perduli sekitar.

Berdasarkan cerita dari sang ibu, H merupakan anak yang aktif, memiliki konsentrasi tinggi, mudah mengingat, dan cepat tanggap. Namun, saat diminta untuk menyebutkan sesuatu yang ia lihat, ia kerapkali kesulitan dalam menyebutkan nama sesuatu yang mewakili objek yang dimaksud. Apabila diajak untuk bernyanyi, ia tidak bisa menyanyikan lagu tersebut, mungkin hanya bisa menyebutkan lirik-lirik lagu tersebut sebanyak 3-5 kata. Menurut ibunya pula, tidak ada riwayat atau cedera selama ia tumbuh, tapi saat berumur dua tahun, ia pernah mengalami kejang-kejang ketika demam.

Objek kajian dalam penelitian ini adaah adalah Pengaruh sosial media Youtube terhadap pemerolehan bahasa anak pengidap keterlambatan berbicara (speech delay). Tahap Pengumpulan data dilakukan dengan cara 1) memberikan sebuah tontonan audio-visual 2) merekam tanggapan narasumber 3) membuat transkip tanggapan narasumber 4) meneliti hasil transkip dengan teori pemerolehan bahasa 5) memberi kesimpulan mengenai pengaruh sosial media Youtube.

\section{HASIL DAN PEMBAHASAN}

Selama proses pengambilan data, narasumber $(\mathrm{H})$, cenderung tidak nyaman dengan pemberian video Youtube bernyanyi di depannya. Saat diminta untuk bernyanyi bersama, ia mengiyakan dan berjanji akan bernyanyi, dengan alasan diberikannya stimulus dengan tujuan menarik perhatiannya.

Namun, saat video ditayangkan, $\mathrm{H}$ tidak bisa melihat video itu terlalu lama, ia langsung mengambil alih ponsel yang berisi video Youtube dan langsung menggerakan jarinya di atas layar dan mencari video-video yang menurutnya lebih menarik. Saat dibiarkan, ia hanya menunjuk-nunjuk ke arah layar ponsel sebagai caranya untuk memberi tahu tentang apa yang ia lihat.

Setelah cukup lama dibiarkan, akhirnya $\mathrm{H}$ mau untuk bernyanyi bersama, dalam beberapa video yang disediakan, $\mathrm{H}$ hanya mau memutar video audio-visual yang menurutnya memiliki gambar menarik. Berikut ini hasil pentranskipan mengenai tanggapan $\mathrm{H}$ atas pemutaran video audio-visual dari Youtube. Pada bagian pengambilan data, dibagi menjadi tiga bagian, 1) respon saat diajak untuk bernyanyi 2) mengikuti lirik lagu 3) respon terhadap gambar video.

Ket. H : Narasumber

$\mathrm{M}$ : Peneliti

$\mathrm{P}$ : Kakak narasumber

Peristiwa 1

M: Ayo, kita nyanyi bareng-bareng yuk!

$\boldsymbol{H}$ : (Mengambil alih ponsel yang berisi video dari Youtube) 
M: Adek mau cokelat nggak? Nanti kakak kasih tapi nyanyi dulu yah! (mengambil ponsel lalu membuat kesepakatan). Adek $H$ suka cokelat nggak?

H: ka "maksudnya "suka" (dia mengambil alih ponsel dari tangan $M$ lalu memilih video-video Youtube yang ia suka. (karena layar ponsel terkunci, $H$ tidak bisa mengakses aplikasi Youtube) ngga sa *maksudnya "nggak bisa".

$\boldsymbol{M}$ : (membimbing $H$ untuk membuka layar kunci ponsel menuju aplikasi Youtube, lalu membuka video Youtube yang memiliki gambar kereta api) Nih, ada kereta api, kita nyanyi lagu naik kereta api, yuk! (Ponsel di ambil alih oleh $M, H$ diminta untuk duduk, memperhatikan layar, lalu ikut bernyanyi. Video diganti menjadi video audio-visual lagu ayam berkotek)

$\boldsymbol{H}$ : (memperhatikan) au.. au... au... "maksudnya "kucing" saat ia melihat di dekatnya ada seekor kucing.

M: Apa? Kucing?

$\boldsymbol{H}:$ : Au.. (menunjuk kucing) iya.

M: H mau nya nonton kucing? Kakak nggak ada film kucing, nih aja nih ada video lagu anjing, ada lagu anjingnya.

$\boldsymbol{H}$ : (mengambil alih ponsel, lalu mencari video yang ia cari, ia memutar sebuah video game anakanak, video tersebut jarang sekali mengeluarkan suara, hanya banyak sebuah gerakan).

$\boldsymbol{P}$ : Itu kan ponsel kakak, balikin nyanyi dulu yuk! (ponsel diambil) Nanti kakak $M$ mau kasih cokelat ayuk nyanyi dulu!

$\boldsymbol{H}$ : (menggeram kesal) uwah, kaka! Kaka tu, aka tu (menunjuk ponsel milik kakaknya)
Peristiwa Tutur 2

(Kembali menyetel video beraudio dengan visual sebuah kereta api, ponsel dipegang oleh $P$ )

$\boldsymbol{H}$ : aku iya (memperhatikan ke layar ponsel tetapi akhirnya berusaha mengambil ponsel dari tangan kakaknya, dan ponsel kembali di tangan $\mathrm{H}$, ia kembali membuka sebuah video yang menampilkan game yaitu sebuah truk yang berhenti di setiap rumah lalu mengangkut barangbarang, sesekali truk tersebut membunyikan klakson). Uuu... Ntaa..

$\boldsymbol{P}$ : Nyanyi aja yuk, dek? Nanti nggak dikasih pinjem ponsel kalo nggak mau nyanyi!

H : Ngga

$\boldsymbol{P}$ : Nyanyi dulu ya sebentar aja, nanti kakak kasih ponsel nya!

$\boldsymbol{H}: Y a$

(Video bertema kereta api kembali di putar, $M$ dan $P$ ikut bernyanyi agar $H$ terpancing untuk bernyanyi)

$\boldsymbol{H}$ : Nta..ntaa (menunjuk ke layar) *maksudnya kereta

$\boldsymbol{P}$ dan $M$ : Iya, itu kereta

$\boldsymbol{H}$ : Ayo... kas naik... itu naa... popo tu, itu popo naa *maksudnya "ayo lekas naik/ itu copot nah, itu copot. (bagian saat di layar ponsel, kereta sedang memisahkan gerbong)

$M$ : Iya itu gerbong keretanya lagi di lepas sama petugas kereta.

Peristiwa Tutur 3

$\boldsymbol{H}$ : Hah, uu... jalan *maksudnya "wah kereta berjalan" (kereta dalam layar ponsel sedang berjalan di atas rel)

$\boldsymbol{M}:$ H pernah naik kereta nggak?

$\boldsymbol{H}$ : Ayuu "maksudnya "ayoo" (H mengira diajak naik kereta)

$\boldsymbol{H}:$ : Tu.. tu.. (menunjuk gambar kereta)

$M$ : Itu tayo tuh, ada gambar tayonya.

$\boldsymbol{H}$ : Huu, tayo. Itu ntaa!

M : Iya, itu kereta. 


\section{H: Uиuиu, jajaaahh *maksudnya} "Dadah"

$\boldsymbol{H}$ : Itu nae, jajahhh *maksudnya "itu naik, dadah"

$\boldsymbol{H}:$ Tayo tu

$\boldsymbol{H}$ : Hee (tertawa melihat kereta) Haaa (melihat ke arah $P$ dan $M$ ).

$\boldsymbol{H}:$ Ut..ut..ut... *maksudnya "tut tut tut" (mempratekan suara kereta)

$\boldsymbol{H}$ : Nah, Tuntun *maksudnya nah, turun"

$\boldsymbol{H}:$ Tut.. Tut...

H : Itu Ntaa, Tu Jlan Tu *maksudnya "nah itu jalan tuh (keretanya)

$\boldsymbol{H}$ : Naa, Apatu (saat ia melihat kereta dengan warna baru)

$\boldsymbol{H}$ : Itu, Aka (menunjuk sebuah rambutan yang sedang di bawa ibunya)

$\boldsymbol{M}:$ H mau rambutan?

$\boldsymbol{H}:$ Mau

(Video selesai diputar).

Dari transkip di atas, narasumber $\mathrm{H}$ sulit sekali untuk di ajak untuk bernyanyi bersama, saat di beri sebuah video Youtube dari ponsel, ia cenderung berfokus untuk bagaimana dirinya dapat mengambil alih ponsel, dari sini terlihat ia kurang nyaman dengan video yang disediakan, yaitu bernyanyi.

Menurut pengakuan ibunya pun, ia sangat sulit diajak untuk bernyanyi atau mengikuti perkataan orang lain. Namun, ia sangat lancar dalam hal meniru. Saat diletakan puzzle, ia dengan cepat meletakan potongan-potongan puzzle tersebut ke tempatnya, begitu pula saat ia diajarkan nama-nama binatang di rumah lewat gambar, ia dengan mudah menunjuk binatang yang diminta, tapi selalu sulit dalam mengucapkan nama binatang tersebut, ia kerapali keliru dalam mengucapkannya. Saat menunjuk gambar "ayam", ia mengucapkan "yap", dengan fonem $/ \mathrm{m} /$ dibaca $/ \mathrm{p} /$.

$\mathrm{H}$ cenderung sulit mengucapkan fonem $/ \mathrm{k} /, / \mathrm{u} /, / \mathrm{c} /, / \mathrm{i} /, / \mathrm{r} / / \mathrm{e} /, / \mathrm{l} /, / \mathrm{s} /, / \mathrm{t} /$ dan kadang /m/ apabila dibarengi dengan huruf-huruf di atas. Dalam peristiwa 1, saat ia ingin menyebutkan kata "kucing", ia lebih memilih menyuarakan suara kucing yang ia anggap "au..au" (miau/miaw), agar kita sebagai pendengar langsung paham dengan apa yang ia maksud. Ia juga jarang melafalkan fonem /i/, seperti saat mau menunjuk sesuatu dengan kata "itu" selalu dilafalkan dengan "tuu" (itu), lala kata "kereta" selalu dilafalkan dengan "ntaa", itu semua terjadi di semua peristiwa tuturan dari $\mathrm{H}$.

Di luar tontonan video, $\mathrm{H}$ memiliki sifat yang tidak mau kalah, dan tidak bisa dicegah, dapat terlihat dengan caranya yang ingin selalu memenag ponsel dan memilih sendiri, ini terlihat jelas di peristiwa 1, di mana belum ada respon dari $\mathrm{H}$ terhadap video yang ingin ditayangkan. $\mathrm{H}$ terlihat lebih menyukai game yang lebih banyak bergerak dan minim suara, ia lebih tenang dan fokus bahkan menampilkan ekspresi tersenyum dengan video game yang menampilkan sebuah truk yang sedang mengangkut barang.

Meskipun stimulus berupa cokelatdengan maksud untuk menarik perhatiannya - sudah diberikan, ia kelihatan tidak perduli, bahkan sesekali ia menunjukan wajah kesal. Pada peristwa 2, ia mulai merespon video Youtube yang ada di layar ponselnya dengan imingiming ponsel dan cokelat akan diberikan kepadanya.

Meskipun begitu, $\mathrm{H}$ tidak merespon banyak dari lagu tersebut, setidaknya katakata yang muncul yang berasal dari video Youtube ada sepuluh yaitu 1) Ayo... 2) kas 3) naik... 4) tu 5) naa... 6) popo 7) tu, 8) tu 9) popo dan 10) naa. Kata-kata yang diucapkan $\mathrm{H}$ terdengar tidak jelas dan banyak fonem-fonem yang dhilangkan. Fonem-fonem seperti /c/, /1/, /k/ dan /s/, /t/ cenderung lesap, bahkan pada kata yang seharusnya "copot" dilafalkan dengan 
“popo', terdapat pelesapan fonem /c/, dan $/ \mathrm{t} /$, dan pengulangan fonem $/ \mathrm{p} / \mathrm{dan} / \mathrm{o} /$.

Penggandaan rangkaian kata ini biasanya muncul pada tahap pralinguistik yaitu usia 0-12 bulan, penggandaan ini disebut dengan masa conical. (Nuryani, 2013, p. 92). Sedangkan pada tahap satukata yaitu usia 12-18 bulan, biasanya bayi mudah mengucapkan konsonan $/ \mathrm{b} /, / \mathrm{p} /$, $/ \mathrm{m} /$, ini seperti yang dilakukan oleh $\mathrm{H}$, ia mudah melafalkan fonem /p/ dibandingkan fonem-fonem lain.

Upaya memahami makna kata yang diucapkan anak pada masa satu kata (1218 bulan) tidak mudah, kadangkali orang tua atau orang lain perlu memperhatikan aktivitas anak dan unsur-unsur nonlinguistik lainnya seperti gerak, isyarat, ekspresi, dan benda yang ditunjuk si anak.

Pada peristiwa 1, saat $\mathrm{H}$ melihat seekor kucing di dekatnya, ia berusaha memberi tahu tentang apa yang ia lihat, namun karena tidak bisa menyebutkannya dengan lancar, maka ia menggunakan sebuah isyarat dengan berusaha meniru suara binatang kucing yang ia dengar, yaitu "au...au..." (miau/miaw). Sampai sini, sudah dapat terlihat bahwa si narasumber $/ \mathrm{H}$ memang mengalami keterlambatan dalam berbicara, apa yang seharusnya muncul saat masa-masa bayi muncul pula di dalam diri $\mathrm{H}$ sebagai anak berusia empat tahun, dan apa yang seharusnya ada di dalam anak berusia empat tahun, tidak muncul dalam diri $\mathrm{H}$, yaitu seperti tuturan yang mulai panjang dan tata bahasanya lebih teratur. Dia tidak hanya menggunakan dua kata, tetapi tiga atau lebih.

Dalam transkip di atas, sudah terlihat dengan jelas bahwa $\mathrm{H}$ masih dalam kesulitan pada fase pelafalan dan bunyi. Ia banyak mengeluarkan bunyibunyi kurang jelas yang menghasilkan makna-makna yang kabur. Fase ini disebut fase fonologis yaitu pada usia 0-2 tahun, yaitu tahap di saat anak-anak bermain dengan bunyi-bunyi bahasa dan mulai mengoceh. $\mathrm{H}$ sudah ada pada tahap sintaksis yaitu rentang usia 2-7 tahun yang ditandai dengan kesadaran gramatis dan berbicara menggunakan kalimat.).

Dalam transkip (bagian peristiwa 3), $\mathrm{H}$ menunjukkan sebuah sikap di mana ia mengetahui sebuah konteks, saat $\mathrm{M}$ bertanya "H pernah naik kereta nggak?" jawaban dari $\mathrm{H}$ adalah "Hayu", ini menunjukan sesungguhnya ia tidak juga bisa dikatakan belum sampai pada tingkat sintaksis.

Dengan melihat data yang ada, sesungguhnya, $\mathrm{H}$ merupakan anak yang cerdas dan cepat tanggap, namun ia kurang dalam hal mendengar, ia cenderung lebih mudah menangkap informasi dengan cara melihat dan meniru. Apabila memperoleh sesuatu lewat pendengaran cenderung tidak digubris dan malah membuat dirinya kelihatan tidak nyaman. Berdasarkan faktor-faktor penyebab gangguan berbahasa speech delay yang sudah disebutkan sebelumnya, $\mathrm{H}$ bukanlah seorang anak yang memiliki penyebab speech delay dengan alasan retardasi mental, karena menurut pengakuan orang tua nya, $\mathrm{H}$ tidak memiliki riwayat penyakit berat atau penyakit turunan.

Begitu pula dengan penyakit kesulitan mendengar, meskipun ia kesulitan dalam memperoleh suatu informasi dalam media audio-visual seperti penelitian di atas, itu tidak bisa dibenarkan karena $\mathrm{H}$ merupakan anak yang mudah paham, meniru dan kerapkali mengikuti apa yang orang lain katakan. Menurut pengakuan dari orang tuanya, ia juga tidak pernah mengalami infeksi atau penyakit turunan dekat bagian telinga, maka alasan ini kurang berterima dengan diri $\mathrm{H}$.

Namun, kemungkinan lain seperti gangguan pada otot bicara perlu dipertimbangkan. Ciri-ciri mengenai penyebab ini dapat dikenali dengan cara $\mathrm{H}$ 
merespon video dari Youtube di atas. $\mathrm{H}$ melafalkan bicara tak jelas dan tak berujung sempurna, otaknya sudah memerintahkan dan memberikan stimulus untuk menjawab dengan benar tapi yang keluar dari mulutnya seringkali tak jelas. Seperti pelafalan kata "kereta" yang diucapkan menjadi "ntaa", kucing jadi "au", "ayam" menjadi "yap", lalu di luar pengambilan data, $\mathrm{H}$ seringkali mengomentari sesuatu dengan menggumamkan sejumlah kata-kata yang tidak dapat dijelaskan maknanya.

Secara kognitif, $\mathrm{H}$ termasuk anak yang pintar dan cakap. Ia dengan mudahnya memasukan sebuah puzzle ke tempat utuhnya yang pada dasarya memiliki sebuah kemampuan menganalisis dan penggunaan pola pikir, dan dari sini juga terlihat bahwa peran orang tua juga membuat pengaruh terhadap penyebab gangguan berbicara pada H. Sepupu H bercerita, H diajarkan menyusun puzzle. Namun, kadang orang tuanya membiarkan anaknya menonton televisi berjam-jam, dan tontonannya pun film-film bisu, yang minim sekali suara. Ia pun seringkali dilarang keluar rumah, karena dianggap nakal. Maka, terdapat dua faktor yang menjadi penyebab munculnya gangguan berbahasa,yaitu faktor 1) dalam tubuh, yakni gangguan pada otot berbicara yang berkaitan dengan gangguan neurologis atau saraf dan dan 2) luar tubuh, faktor orang tua, seperti interaksi dan komunikasi.

\section{KESIMPULAN}

Berdasarkan analisis yang telah dilakukan dapat disimpulkan bahwa media sosial media Youtube memiliki pengaruh yang signifikan terhadap pemerolehan bahasa anak usia 3-4 tahun. Demikian juga pada anak yang mengalami speech delay. Media sosial youtube dapat digunakan sebagai media untuk membantu anak-anak yang mengalami keterlambatan bicara untuk mengenalkan kosa kata.
Responden $\mathrm{H}$ sedang berada dalam dua (2) fase pemerolehan bahasa yaitu 1) pralinguistik; di mana ia menggandakan sejumlah kata yang dalam fase pralinguistik disebut conical 2) Tahap satu-kata. Pada tahap ini $\mathrm{H}$ dominan dalam pelafalan $/ \mathrm{b} /, \quad / \mathrm{p} /$ dan $/ \mathrm{m} /$ dibandingkan sejumlah konsonan lain. Selain itu, dalam pelafalan dan membunyikan suatu kata responden cenderung belum jelas, tetapi secara sintaksis, ia dengan sadar mengerti sebuah konteks percakapan dan memiliki kesinambungan dalam penyampaiannya.

Dari analisis tersebut, kemungkinan besar penyebab $\mathrm{H}$ mengalami gangguan berbahasa ialah 1) gangguan otot bicara yang berkaitan langsung dengan saraf 2) kurangnya interaksi dan komunikasi dengan orang tua.

Banyaknya perbendaharaan kata yang ada di dalam media Youtube bisa mempengaruhi $\mathrm{H}$, jika $\mathrm{H}$ memiliki kesadaran berkomunikasi dan mendengar yang baik, namun sejauh ini, akibat kedua faktor di atas, $\mathrm{H}$ mengalami kesulitan dalam menerima sejumlah stimulus positif dari media Youtube. Tapi, apabila ini segera dibicarakan oleh ahli dan adanya perubahan positif yakni kesadaran orang tua dan lingkungan, tentu $\mathrm{H}$ akan menjadi pribadi yang lebih baik.

\section{DAFTAR PUSTAKA}

Dardjowidjojo, Soenjono. (2010). Psikolinguistik: Pengantar Pemahaman Bahasa Manusia. Jakarta: Yayasan Obor Indonesia.

Hernawati. (2007). "Pengembangan Kemampuan Berbahasa dan Berbicara Anak Tunarungu". Jurnal JASSI anakku Vol. 7 No.1 Juni 2007 hlm 101-110.

Lestari, Asti Ramadhani Endah. (2018). Kesadaran Fonologis pada Anak Usia 3 Tahun, dalam Fon: Jurnal Pendidikan Bahasa dan Sastra 


\section{Indonesia, Volume 12 No. 1 tahun} 2018.

Nuryani dan Dona Aji K.P. (2013). Psikolinguistik. Ciputat: Mazhab Ciputat.

Subyantoro. (2013). Gangguan Berbahasa. Yogyakarta: Penerbit Ombak.
Yanti, Prima Gusti. (2016). "Pemerolehan Bahasa Anak: Kajian Aspek Fonologi Pada Anak Usia 2 - 2,5 Tahun". No. 2, Vol. 1, Desember 2016 